\title{
Neurotoxic Basolateral Amygdala Lesions Impair Learning and Memory But Not the Performance of Conditional Fear in Rats
}

\author{
Stephen Maren \\ Department of Psychology and Neuroscience Program, University of Michigan, Ann Arbor, Michigan 48109-1109
}

We examined the influence of extensive overtraining (75 trials) on the impact of neurotoxic basolateral amygdala (BLA) lesions on Pavlovian fear conditioning in rats. As we have shown previously, pretraining BLA lesions yielded severe deficits in the acquisition of conditional freezing in rats trained with either 1 or 25 conditioning trials. However, extensive overtraining (50 or 75 trials) mitigated deficits in conditional freezing. Under these conditions the rats with BLA lesions expressed normal and robust freezing behavior, although they required at least 10 times as much training as control rats to reach this level of performance. The ability of rats with BLA lesions to acquire and express conditional freezing after extensive overtraining was modality-specific; conditional freezing in individual rats was acquired to contextual, but not acoustic, conditional stimuli. These results suggest that neural circuitry outside of the amygdala can mediate contextual fear conditioning under some conditions. In contrast to pretraining lesions, post-training BLA lesions eradicated the memory for Pavlovian fear in rats trained with either 1 or 75 trials; this deficit was not modality-specific. Together, these results reveal that impairments in the acquisition and expression of conditional fear in rats with BLA lesions are not attributable to deficits in the performance of the freezing response but are attributable to disruptions in the learning and memory of Pavlovian fear conditioning.

Key words: amygdala; NMDA; lesion; overtraining; learning; memory; conditioning; freezing; fear
Considerable progress has been made in elucidating the neural substrates of emotional learning and memory in mammals (Lavond et al., 1993; Fanselow, 1994; Maren, 1996; McGaugh et al., 1996; Davis, 1997; LeDoux, 1998). One form of aversive learning that has served as the primary model for studying the neural substrates of emotional learning and memory is Pavlovian fear conditioning in rats. Several investigators have demonstrated that both the acquisition and expression of conditional fear require neurons in the basolateral amygdala (BLA; Sananes and Davis, 1992; Campeau and Davis, 1995; Lee et al., 1996; Cousens and Otto, 1998). For example, we have shown that neurotoxic lesions of the BLA abolish conditional freezing (immobility except for breathing) when the lesions are made either 1 week before or up to 1 month after training (Maren et al., 1996a) and even when they are made after moderate overtraining (Maren, 1998). Moreover, reversible inactivation of the BLA (Helmstetter and Bellgowan, 1994; Muller et al., 1997) or intra-BLA inf usion of NMDA receptor antagonists (Miserendino et al., 1990; Fanselow and Kim, 1994; Maren et al., 1996b; Lee and Kim, 1998) prevents the acquisition of conditional fear.

Although these results are consistent with a role for the BLA in associative processes in fear conditioning (i.e., encoding and storing fear memories; Maren and Fanselow, 1996; Fanselow and LeDoux, 1999), they nonetheless are open to alternative interpretations. For example, McGaugh and colleagues have argued that the BLA is not essential for encoding and storing fear memories but, rather, is critically involved in the performance of fear re-

\footnotetext{
Received June 7, 1999; revised July 10, 1999; accepted July 21, 1999.

This work was supported by grants from the National Institute of Mental Health (R29MH57865) and the University of Michigan. I thank Bill Holt and Ki Goosens for technical assistance.

Correspondence should be addressed to Dr. Stephen Maren, Department of Psychology, University of Michigan, 525 East University Avenue, Ann Arbor, MI 48109-1109.

Copyright (C) 1999 Society for Neuroscience $\quad 0270-6474 / 99 / 198696-08 \$ 05.00 / 0$
}

sponses, such as freezing (Cahill and McGaugh, 1998; Cahill et al., 1999). In support of this view, they recently have reported that rats with neurotoxic BLA lesions learn to avoid a compartment in which footshock was delivered, despite exhibiting robust deficits in conditional freezing (Vazdarjanova and McGaugh, 1998). Thus, although associative models of BLA function do not rest solely on studies examining freezing behavior (Fanselow and LeDoux, 1999), they must contend with the fact that freezing behavior has yet to be observed in rats with BLA lesions (Maren et al., 1996a).

A key question, then, is whether or not rats with neurotoxic BLA lesion are ever capable of exhibiting freezing behavior. Recently, we reported that moderate overtraining (25 trials) generates low levels of conditional freezing (30-40\%) in rats with pretraining BLA lesions (Maren, 1998). This result is interesting because it suggests that more extensive overtraining might generate normal levels of conditional freezing in rats with BLA lesions. Such a finding would bolster associative models of BLA function in fear conditioning and temper the claim that freezing impairments in rats with BLA lesions are merely attributable to performance deficits. To address this issue, the present experiments examined whether extensive overtraining (75 trials) would yield conditional freezing in rats with pretraining neurotoxic BLA lesions and, if so, whether this level of training also would immunize rats against the normally deleterious effects of posttraining BLA lesions. Both contextual and auditory fear conditioning were examined.

\section{MATERIALS AND METHODS}

Subjects. The subjects were 204 adult male Long-Evans rats (200-224 $\mathrm{gm}$ ) obtained from a commercial supplier (Harlan Sprague Dawley, Indianapolis, IN). After arrival, the rats were housed individually in standard stainless-steel hanging cages on a 14/10 hr light/dark cycle (lights on at 7:00 A.M.) and were provided free access to food and tap water. After being housed, the rats were handled daily (10-20 sec per rat) for $5 \mathrm{~d}$ to acclimate them to the experimenter. 
Behavioral apparatus. Eight identical observation chambers $(30 \times 24 \times$ $21 \mathrm{~cm}$; MED Associates, Burlington, VT) were used for both conditioning and contextual fear testing. The chambers were constructed from aluminum (side walls) and Plexiglas (rear wall, ceiling, and hinged front door) and were situated in sound-attenuating cabinets located in a brightly lit and isolated room. The floor of each chamber consisted of 19 stainless steel rods (4 mm diameter) spaced $1.5 \mathrm{~cm}$ apart (center-tocenter). The rods were wired to a shock source and solid-state grid scrambler (MED Associates) for the delivery of footshock unconditional stimuli (USs). A speaker mounted outside a grating in one wall of the chamber was used for the delivery of acoustic conditional stimuli (CSs). The chambers were cleaned with a $5 \%$ ammonium hydroxide solution, and stainless steel pans containing a thin film of the same solution were placed underneath the grid floors before the rats were placed inside. Ventilation fans in each chest supplied background noise $(65 \mathrm{~dB}, \mathrm{~A}$ scale).

Each conditioning chamber rested on a load-cell platform that was used to record chamber displacement in response to each rat's motor activity. To ensure interchamber reliability, we calibrated each load-cell amplifier to a fixed chamber displacement. The output of the load cell of each chamber was set to a gain $($ Vernier dial $=8)$ that was optimized for detecting freezing behavior. Load-cell amplifier output $(-10$ to $+10 \mathrm{~V})$ from each chamber was digitized and acquired on-line, using Threshold Activity software (MED Associates). The absolute values of the load-cell voltages were computed, and these absolute values were multiplied by 10 to yield a load-cell activity scale that ranged from 0 to 100 .

During both the conditioning and extinction sessions each rat's activity was monitored continuously, using the data acquisition system described above. For each chamber the load-cell activity was digitized at $5 \mathrm{~Hz}$, yielding one observation per rat every $200 \mathrm{msec}$ (300 observations per rat per minute). In all experiments, freezing was quantified by computing the number of observations for each rat that had a value less than the freezing threshold (load-cell activity $=5$; animals exhibit freezing when the load-cell activity is at or below this value; see Maren, 1998). To avoid counting momentary inactivity as freezing, we scored an observation as freezing only if it fell within a contiguous group of at least five observations that were all less than the freezing threshold. Thus, freezing was scored only if the rat was immobile for at least $1 \mathrm{sec}$. For each session the freezing observations were transformed to a percentage of total observations. In addition to freezing, motor activity was quantified during the preshock period on the conditioning day by using the raw load-cell output.

Surgery. Rats were treated with atropine methyl nitrate $(0.4 \mathrm{mg} / \mathrm{kg}$ body weight), anesthetized with an intraperitoneal injection of Nembutal (sodium pentobarbital, $65 \mathrm{mg} / \mathrm{kg}$ body weight), and mounted in a stereotaxic apparatus (David Kopf Instruments, Tujunga, CA). The scalp was incised and retracted, and the head position was adjusted to place Bregma and lambda in the same horizontal plane. Small burr holes (2 $\mathrm{mm}$ diameter) were drilled bilaterally in the skull for the placement of 28-gauge cannula in the basolateral amygdala $(3.3 \mathrm{~mm}$ posterior to Bregma; $5.0 \mathrm{~mm}$ lateral to the midline). A $10 \mu \mathrm{l}$ Hamilton syringe was mounted in an infusion pump (Harvard Apparatus, South Natick, MA) and connected to the injection cannula with polyethylene tubing. NMDA $(20 \mu \mathrm{g} / \mu \mathrm{l}$; Sigma, St. Louis, MO) in $100 \mathrm{~mm}$ PBS, pH 7.4, was infused $(0.1 \mu \mathrm{l} / \mathrm{min}) 8.0 \mathrm{~mm}$ ventral to brain surface $(0.2 \mu \mathrm{l})$ and $7.5 \mathrm{~mm}$ ventral to brain surface $(0.1 \mu \mathrm{l})$ for each penetration. After each infusion $5 \mathrm{~min}$ were allowed for diffusion of the drug. After surgery the incision was closed with stainless steel wound clips, and the rats were allowed to recover on a heating pad before returning to their home cage.

Experiment 1: Pretraining BLA lesions and contextual fear conditioning. Rats $(n=128)$ were assigned randomly to a $2 \times 4$ factorial design with factors of surgery (sham or BLA lesion) and training trials $(1,25,50$, or 75 trials). Fourteen rats were excluded from the experiment because of misplaced lesions. This yielded the following groups: $\mathrm{SH}-1(n=16)$, BL-1 $(n=13)$, SH-25 $(n=16)$, BL-25 $(n=12)$, SH-50 $(n=16)$, BL-50 $(n=12)$, SH-75 $(n=16)$, and BL-75 $(n=13)$. All rats received either sham surgery or neurotoxic BLA lesions 1 week before fear conditioning. On the conditioning day the rats were transported to the laboratory in squads of eight and placed in the conditioning chambers; the chamber position was counterbalanced for each squad and group. The rats received unsignaled footshock ( $2 \mathrm{sec}, 1.0 \mathrm{~mA}$; $60 \mathrm{sec}$ intertrial interval; 1 , 25,50 , or 75 trials) $3 \mathrm{~min}$ after being placed in the chambers. At $60 \mathrm{sec}$ after the final shock the rats were returned to their home cages. Then 24 $\mathrm{hr}$ after training, fear conditioning to the context of the conditioning chamber was assessed by returning the rats to the conditioning chambers and measuring freezing behavior (somatomotor immobility except that necessitated by breathing) during an 8 min extinction test.

Experiment 2: Post-training BLA lesions and contextual fear conditioning. Rats $(n=46)$ were assigned randomly to a $2 \times 2$ factorial design with factors of surgery (sham or BLA lesion) and training trials (1 or 75 trials). Four subjects were excluded because of death or misplaced lesions, yielding the following groups: SH-1 $(n=11)$, BL-1 $(n=11)$, SH-75 $(n=10)$, and BL-75 $(n=10)$. On the conditioning day the rats were transported to the laboratory in squads of eight and placed in the conditioning chambers; the chamber position was counterbalanced for each squad and group. The rats received unsignaled footshock $(2 \mathrm{sec}, 1.0$ $\mathrm{mA}$; $60 \mathrm{sec}$ intertrial interval; 1 or 75 trials) 3 min after being placed in the chambers. At $60 \mathrm{sec}$ after the final shock the rats were returned to their home cages. The rats received either sham surgery or BLA lesions $1 \mathrm{~d}$ after fear conditioning. Then 1 week after their recovery from surgery, fear conditioning to the context of the conditioning chamber was assessed by returning the rats to the conditioning chambers and measuring freezing behavior during an 8 min extinction test.

Experiment 3: Pre- or post-training lesions and auditory fear conditioning. Rats $(n=30)$ were assigned randomly to a $2 \times 2$ factorial design with factors of surgery (sham or BLA lesion) and time-of-lesion (pretraining or post-training). This assignment yielded four groups: SH-Pre $(n=6)$, BL-Pre $(n=8)$, SH-Post $(n=8)$, and BL-Post $(n=8)$. Rats received sham surgery or BLA lesions either 1 week before or $1 \mathrm{~d}$ after fear conditioning, which consisted of 75 signaled footshock trials. On the conditioning day the rats were transported to the laboratory in squads of eight and placed in the conditioning chambers; the chamber position was counterbalanced for each squad and group. The rats received 75 tone $(90$ $\mathrm{dB}, 10 \mathrm{sec}, 2 \mathrm{kHz}$ ) footshock (2 sec, $1.0 \mathrm{~mA} ; 70 \mathrm{sec}$ intertrial interval) trials $3 \mathrm{~min}$ after being placed in the chambers. At $60 \mathrm{sec}$ after the final shock the rats were returned to their home cages. Then 1 week after training (to allow for recovery from surgery in the post-training groups), fear conditioning to the context of the conditioning chamber was assessed by returning the rats to the conditioning chambers and measuring freezing behavior during an 8 min extinction test. At $24 \mathrm{hr}$ after the context extinction test, fear to the tone CS was measured by placing the rats in a novel context and presenting a 6 min tone 2 min after placement in the context. The tone testing was performed in the chambers described above, except that the room housing the chambers was darkened (illumination in the room was provided by a $40 \mathrm{~W}$ red light), the doors on the sound-attenuating cabinets were closed, the ventilation fans were turned off, and the chambers were cleaned with a $1 \%$ acetic acid solution.

Histology. Histological verification of lesion location was performed after behavioral testing. Rats were perfused across the heart with $0.9 \%$ saline, followed by $10 \%$ formalin. After extraction from the skull, the brains were post-fixed in $10 \%$ formalin for $2 \mathrm{~d}$ and $10 \%$ formalin $/ 30 \%$ sucrose until sectioning. Coronal sections $(50 \mu \mathrm{M}$ thick, taken every 200 $\mu \mathrm{M})$ were cut on a cryostat $\left(-16^{\circ} \mathrm{C}\right)$ and wet-mounted on glass microscope slides with $70 \%$ ethanol. After being dried, the sections were stained with $0.25 \%$ thionin to visualize the neuronal cell bodies. Lesions were verified by reconstructing the damage on stereotaxic atlas templates.

Data analysis. For each session the freezing data were transformed to a percentage of total observations, a probability estimate that is amenable to analysis with parametric statistics. These probability estimates of freezing were analyzed by ANOVA. Post hoc comparisons in the form of Fisher Protected Least Significant Difference tests were performed after a significant omnibus $F$ ratio. All data are represented as the means \pm SEMs.

\section{RESULTS Histology}

Neurotoxic BLA lesions were comparable in all three experiments and similar to those described in previous reports (Maren et al., 1996a; Maren, 1998). Figure 1 displays a photomicrograph of a representative lesion, and Figure 2 illustrates the maximum and minimum extent of the lesions. There was extensive damage to the basolateral complex of the amygdala, including the lateral, basolateral, and basomedial nuclei. The central amygdaloid nucleus was spared, although there was minimal damage to its most caudal aspect in some cases. There was damage to the posterior amygdala, the amygdalo-hippocampal area, and the entorhinal 


\section{Low Power (7X)}
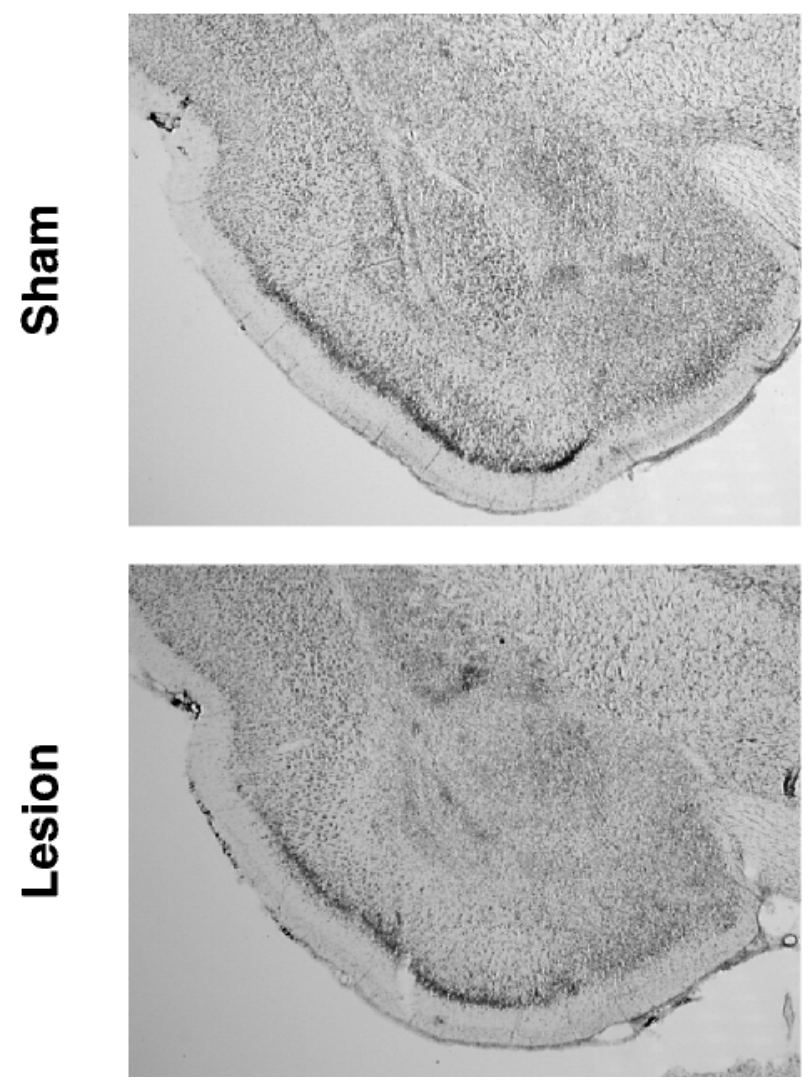

High Power (25X)
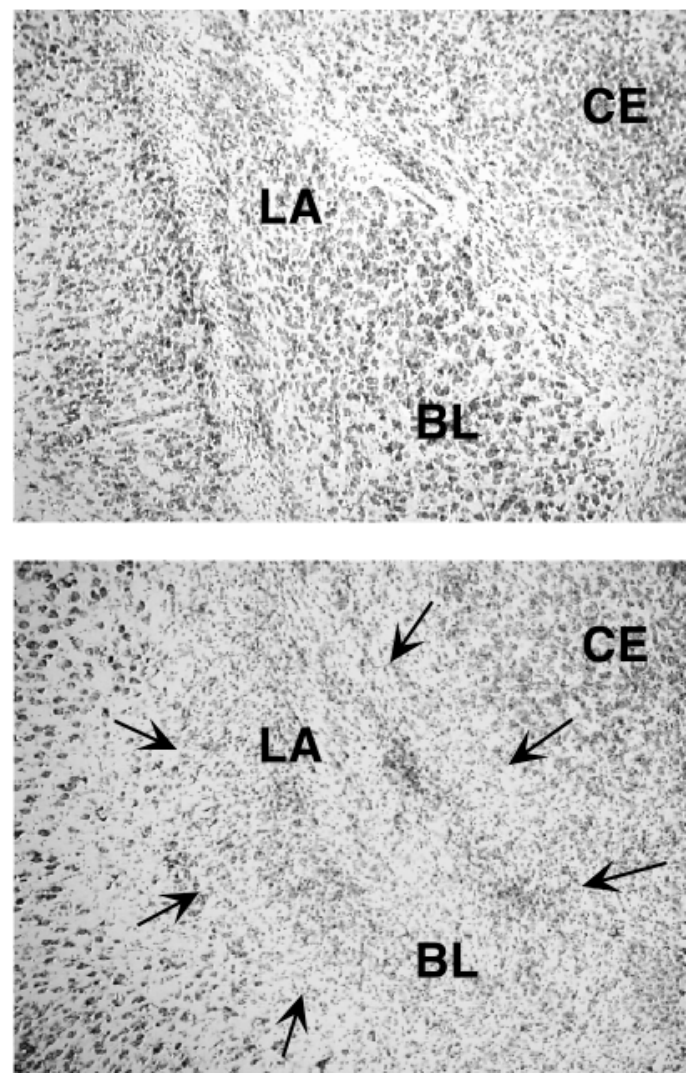

Figure 1. Photomicrographs of thionin-stained brain sections at low and high magnifications from representative rats receiving either sham surgery or a neurotoxic BLA lesion. The lesion (indicated by arrows) was confined to the basolateral amygdaloid complex. $B L$, basolateral; $C E$, central nuclei of the amygdala; $L A$, lateral nuclei of the amygdala.

cortex in some cases; the perirhinal cortex was intact in all cases. Rats with mainly unilateral or partial BLA bilateral lesions were excluded from the statistical analyses (see group assignments above).

\section{Behavior}

The first experiment examined the impact of extensive overtraining on the acquisition of contextual freezing in rats with pretraining neurotoxic BLA lesions. Figure 3 shows freezing in rats with neurotoxic BLA lesions (BL) and sham $(\mathrm{SH})$ rats during an $8 \mathrm{~min}$ context extinction test that was conducted $24 \mathrm{hr}$ after various amounts of training $(1,25,50$, or 75 trials $)$. It is apparent that the amount of training (the number of training trials) determined the severity of freezing deficits in rats with pretraining BLA lesions. That is, rats with BLA lesions exhibited severe impairments in freezing during the $8 \mathrm{~min}$ extinction test after receiving either 1 or 25 conditioning trials, but they exhibited normal and high levels of freezing after receiving 50 or 75 conditioning trials. These impressions were confirmed by a two-way ANOVA with variables of group (lesion or sham) and trials $(1,25,50$, or 75 trials). The ANOVA revealed a significant main effect of group $\left[F_{(1,106)}=\right.$ 52.1; $p<0.0001]$ and trial $\left[F_{(3,106)}=24.8 ; p<0.0001\right]$ and a significant Group $\times$ Trial interaction $\left[F_{(3,106)}=6.1 ; p<0.001\right]$. Thus, rats with BLA lesions exhibit normal freezing behavior after extensive overtraining (75 trials), although the rate at which they reach this behavioral asymptote was severely retarded as compared with rats receiving sham surgery. Nonetheless, rats with BLA lesions did acquire conditional freezing after 75 trials, and this implies that there is a second neural substrate capable of mediating fear conditioning during extensive overtraining.

Unconditional freezing to the context of the conditioning chamber (i.e., freezing elicited by the novelty of the chamber) before footshock delivery was not affected by neurotoxic BLA lesions (mean \pm SEM; SH, $9.0 \pm 1.5 \%$; BL, $8.6 \pm 2.0 \% ; F<1$ ). This suggests that unconditional freezing in rats with BLA lesions is intact, at least at the very low levels of freezing that are associated with exposure to a novel context.

The first experiment reveals that extensive overtraining mitigates the effects of pretraining neurotoxic BLA lesions on the acquisition of contextual fear conditioning. The second experiment was conducted to ascertain whether extensive overtraining would protect or immunize rats against the normally deleterious effects of post-training neurotoxic BLA lesions on contextual freezing. Figure $4 A$ shows freezing during an 8 min context extinction test in rats that received neurotoxic BLA lesions or sham surgery $1 \mathrm{~d}$ after training with either 1 or 75 conditioning trials. As shown, the rats receiving post-training BLA lesions exhibited massive impairments in the expression of contextual freezing independent of the amount of presurgical training. These impressions were confirmed by a two-way ANOVA with variables of group (lesion or sham) and trials (1 or 75 trials). The ANOVA revealed a significant main effect of group $\left[F_{(1,38)}=\right.$ 129.3; $p<0.0001$ ] and a nonsignificant main effect of trial and a 


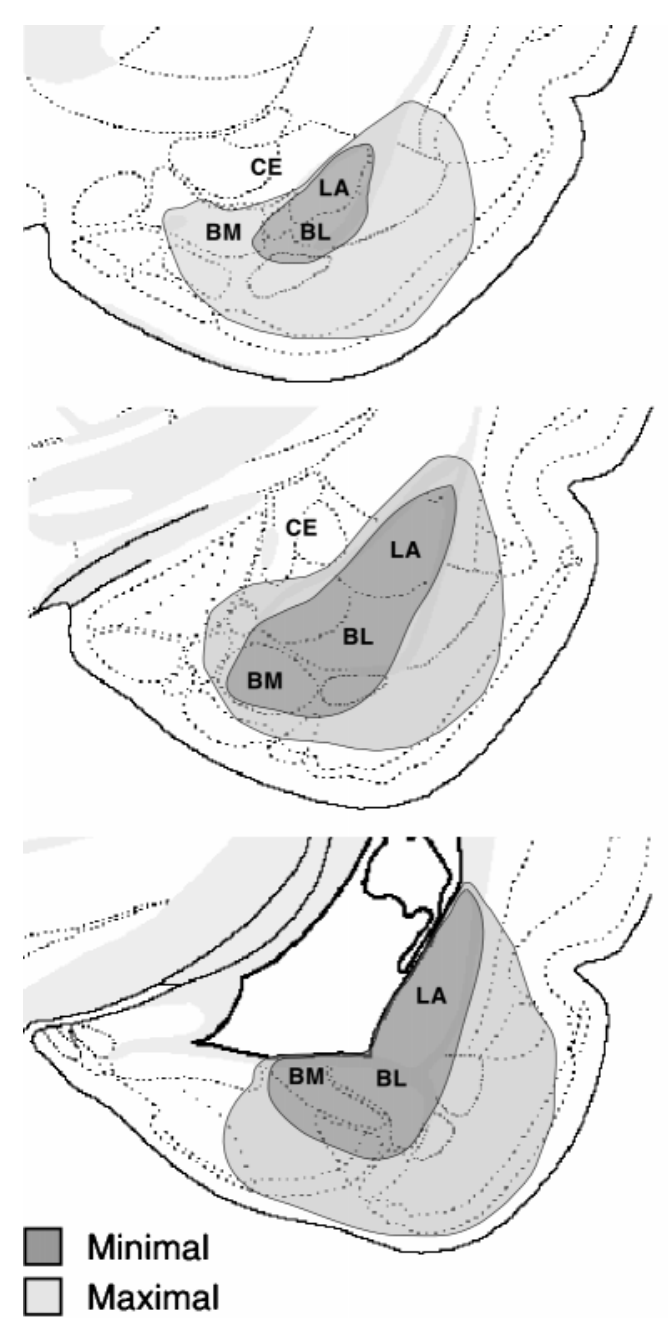

Figure 2. Schematic diagram illustrating the maximum (light gray) and minimum (dark gray) extents of lesions in the amygdala. In general, the lesions were confined to the lateral $(L A)$, basolateral $(B L)$, and basomedial $(B M)$ nuclei.

nonsignificant Group $\times$ Trial interaction $(F$ values $<1)$. Thus, extensive overtraining ( 75 trials) did not immunize rats against the deleterious effects of neurotoxic BLA lesions. This confirms and extends our earlier report in which we found that moderate overtraining (25 trials) did not mitigate the effects of post-training BLA lesions (Maren, 1998). However, both of these results stand in contrast to those in instrumental escape tasks in which overtraining has been reported to mitigate the effects of post-training amygdala lesions (Brady et al., 1954; Parent et al., 1992, 1994; Thatcher and Kimble, 1966) (for a discussion of this issue, see Maren, 1998).

The results of Experiment 2 suggest that the neural system that is engaged by extensive overtraining in rats with BLA lesions (Experiment 1) normally is not engaged by extensive overtraining in intact rats. Otherwise, extensive overtraining in Experiment 2 should have mitigated the effects of post-training BLA lesions. To explore this possibility further, we examined reacquisition of contextual freezing in the same rats used in Experiment 2 by administering two additional conditioning sessions ( 25 trials per session). As shown in Figure $4 B$ and consistent with Experiment 1 , both groups of BLA rats slowly reacquired the conditional freezing response after additional training. Importantly, however,

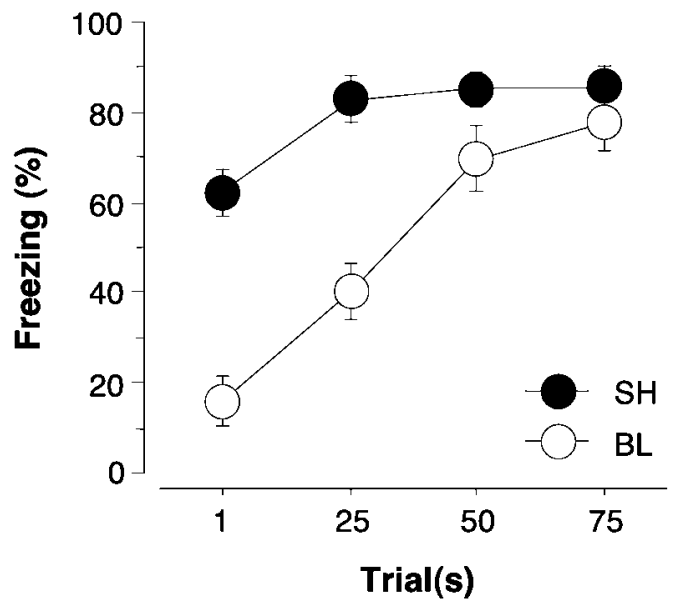

Figure 3. Mean \pm SEM percentage of freezing during an 8 min extinction test in rats receiving sham surgery $(\mathrm{SH})$ or neurotoxic basolateral amygdala lesions $(B L) 1$ week before training with either $1,25,50$, or 75 unsignaled shocks. The extinction test was conducted $24 \mathrm{hr}$ after training. Pretraining BLA lesions severely retarded the acquisition of contextual freezing, although normal asymptotic performance was achieved after 75 conditioning trials.

the rate at which the BLA rats reacquired contextual freezing was independent of the level of original training. That is, BLA rats trained with 75 trials before surgery reacquired at the same rate as BLA rats trained with one trial. Thus, there were no behavioral savings for original acquisition in the BLA rats that had received 75 original training trials. Moreover, the presentation of footshock during reacquisition, which may have served as a reminder for original training (Spear, 1973), did not rapidly instate performance in rats with BLA lesions. This suggests that fear memories in intact rats are formed and stored (at least $1 \mathrm{~d}$ after training) in the BLA and are therefore exquisitely sensitive to disruption by post-training BLA lesions. It is also important to note that these data reveal an important within-subjects demonstration of the associative deficits in rats with BLA lesions. That is, individual BLA rats exhibited normal (and high) levels of freezing after reacquisition training despite exhibiting severely impaired freezing during their first context extinction test. Thus, it cannot be argued that freezing deficits obtained in the initial context extinction test were attributable to a performance failure - clearly, the rats were capable of exhibiting the freezing response when given subsequent extensive overtraining.

It is well known that the training-to-test interval (i.e., the retention interval) can interact with the level of initial training to affect the performance of some aversive memories (Schulenberg et al., 1971; Spear, 1973). In our experiments the retention interval ranges from 1 to $7 \mathrm{~d}$. To examine whether the conditional freezing we established in rats with BLA lesions survives a longer retention interval, we administered a second extinction test to a subset of the Experiment 2 rats $24 \mathrm{~d}$ after their last reacquisition session. This test revealed that conditional freezing was retained in rats with BLA lesions and that there was no forgetting in either the rats with BLA lesions or the sham controls (data not shown). This indicates that fear memories in rats with BLA lesions are durable over relatively long retention intervals once they are established by extensive overtraining.

The first two experiments explored the impact of extensive overtraining on the acquisition and expression of contextual fear 


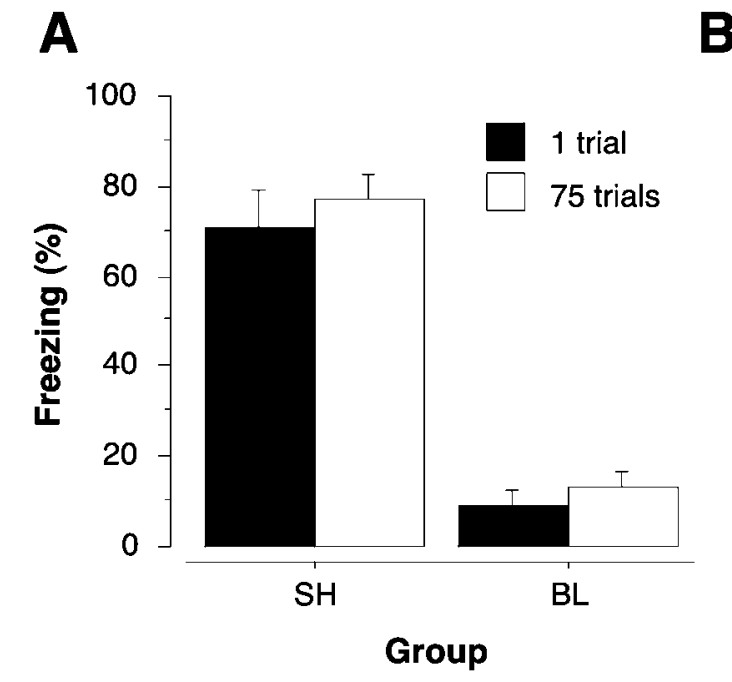

B

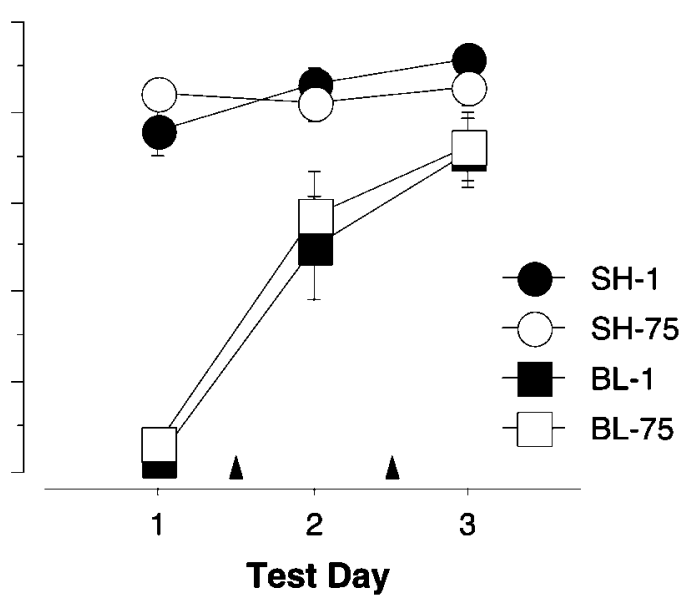

Figure 4. A, Mean \pm SEM percentage of freezing during an 8 min extinction test in rats receiving sham surgery $(\mathrm{SH})$ or neurotoxic basolateral amygdala lesions $(B L) 1 \mathrm{~d}$ after training with either 1 or 75 unsignaled shocks. The extinction test was conducted 1 week after training. Extensive overtraining did not mitigate the deleterious effects of post-training BLA lesions. $B$, Mean \pm SEM percentage of freezing during 4 min extinction tests in rats receiving sham surgery $(S H)$ or neurotoxic basolateral amygdala lesions $(B L)$. The data from Test 1 represent the first 4 min of the 8 min data shown in $A$. Tests 2 and 3 represent 4 min extinction tests conducted after reacquisition sessions, which consisted of 25 unsignaled footshocks (indicated by arrowheads). A single reacquisition session was interposed between Tests 1 and 2 and Tests 2 and 3 . The rate of reacquisition of conditional freezing in rats with BLA lesions was independent of the amount of original training; there were no savings in rats with post-training BLA lesions.
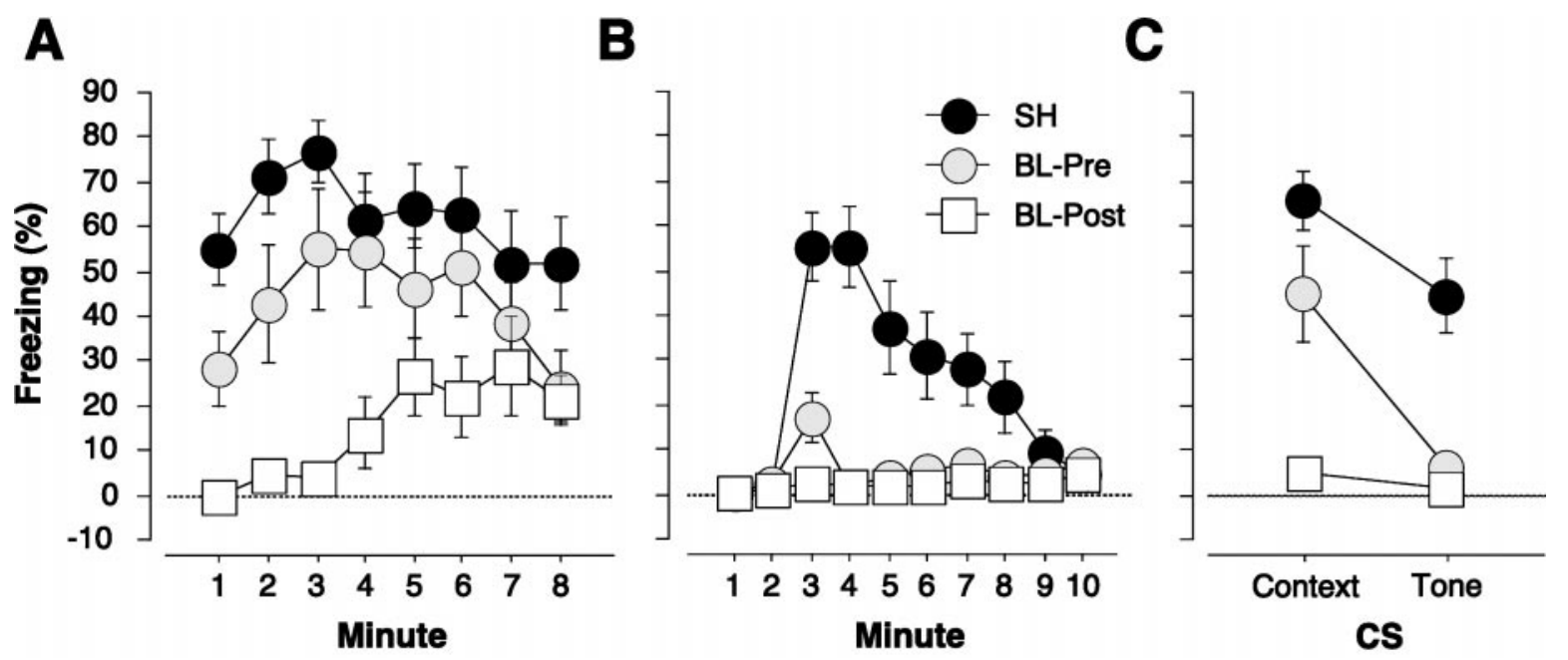

Figure 5. Mean \pm SEM percentage of freezing during an 8 min context $(A)$ and tone $(B)$ extinction test in rats receiving sham surgery $(S H)$ or neurotoxic basolateral amygdala lesions either 1 week before $(B L-P r e)$ or $1 \mathrm{~d}$ after $(B L-P o s t)$ training with 75 signaled shocks. The extinction tests were conducted 1 week after training. The 1 min means are displayed to illustrate the time course of contextual freezing over the duration of the extinction test. Tone onset occurred at the start of the third minute of the tone extinction test. Auditory freezing was abolished by BLA lesions irrespective of whether the lesions were made before or after training. In contrast, only post-training BLA lesions abolished contextual freezing. This interaction is displayed in $C$, which shows the mean \pm SEM percentage of freezing during the first 4 min of the context and tone extinction tests $(A, B)$. Thus, the effect of extensive overtraining was modality-specific and dependent on the timing of the lesions with respect to fear conditioning.

conditioning in rats with BLA lesions. However, the BLA also has been implicated in the acquisition and expression of conditional fear to discrete cues, such as tone CSs, and the discrete nature of these cues might alter how extensive overtraining interacts with the effects of BLA lesions. In fact, it has been reported that deficits in auditory fear conditioning in rats with BLA lesions can be overcome by extensive overtraining in a conditional punishment paradigm (Killcross et al., 1997). Therefore, the third experiment examined whether neurotoxic BLA lesions mitigate either the acquisition or expression of auditory fear conditioning after extensive overtraining. Rats were trained with 75 tone/ footshock conditioning trials either 1 week after (pretraining group) or $1 \mathrm{~d}$ before (post-training group) surgery. Figure 5, $A$ and $B$, shows the context and tone extinction tests, respectively, for rats receiving either sham surgery $(\mathrm{SH})$ or neurotoxic BLA lesions before (BL-Pre) or after (BL-Post) auditory fear conditioning (the pre- and post-training sham groups did not differ significantly from each other and were collapsed for clarity). Consistent with Experiments 1 and 2, neurotoxic BLA lesions eliminated the expression, but not the acquisition, of freezing to the contextual CS (Fig. 5A). However, a different pattern of results was obtained in the tone extinction test. In this case, neurotoxic BLA lesions eliminated both the acquisition and expression of conditional freezing to the auditory CS. This pattern 
of results is illustrated in Figure $5 C$, which shows the mean of the first 4 min of each extinction test.

The differential effect of neurotoxic BLA lesions on the acquisition and expression of conditional freezing to tone and context CSs was confirmed by a two-way ANOVA with factors of group (sham, BL-Pre, or BL-Post) and CS (context or tone). This analysis, which was performed on the 4 min means, revealed a significant main effect of group $\left[F_{(2,27)}=19.0 ; p<0.0001\right]$ and CS $\left[F_{(1,27)}=20.9 ; p<0.0001\right]$ and, importantly, a significant Group $\times \mathrm{CS}$ interaction $\left[F_{(2,27)}=4.0 ; p<0.05\right]$. Post hoc comparisons $(p<0.05)$ indicated that both pre- and post-training lesions impaired freezing to the tone CS; however, only posttraining lesions impaired freezing to the context CS. Thus, extensive overtraining does not mitigate the effects of neurotoxic BLA lesions on either the acquisition or expression of auditory fear conditioning, unlike contextual fear conditioning. These results indicate that the deficits in tone freezing cannot be the result of freezing performance deficits (Cahill and McGaugh, 1998; Vazdarjanova and McGaugh, 1998; Cahill et al., 1999) insofar as the same rats that exhibited impaired tone freezing also exhibited high levels of freezing to the context CS. These results suggest that the BLA is absolutely essential for the acquisition and expression of auditory fear conditioning, and that deficits in auditory fear conditioning are not attributable to deficits in the performance of freezing behavior. Interestingly, the differential effects of BLA lesions on auditory and contextual conditioning also have been reported for measures of lick suppression (to index tone conditioning) and place preference (to index context conditioning; Selden et al., 1991).

\section{DISCUSSION}

The present results shed light on the nature and causes of impairments in Pavlovian fear conditioning in rats with neurotoxic BLA lesions. Experiments 1 and 2 demonstrate that rats with BLA lesions show marked deficits in both the acquisition and expression of contextual fear conditioning. Freezing deficits in rats with pretraining BLA lesions were overcome by extensive overtraining, although extensive overtraining in intact rats did not mitigate the deleterious effects of post-training BLA lesions. The ability of extensive overtraining to mitigate freezing deficits in rats with BLA lesions was modality-specific, insofar as rats with BLA lesions were unable to acquire or express auditory fear conditioning even after extensive overtraining. Collectively, these results define a narrow set of conditions under which intact performance of conditional freezing is obtained in rats with BLA damage. These findings have important implications for understanding the role of the BLA in learning versus performing conditional fear responses. Moreover, they reveal that neural systems outside of the amygdala can mediate some forms of fear conditioning, at least after extensive overtraining, in rats with BLA lesions.

Nearly unanimous consensus has emerged regarding the important role for the BLA in aversively motivated learning (Fanselow, 1994; Maren, 1996; McGaugh et al., 1996; Davis, 1997; LeDoux, 1998; Fanselow and LeDoux, 1999), although there has been recent debate concerning its precise role in the learning versus performance of conditional fear responses in Pavlovian paradigms (Cahill and McGaugh, 1998; Maren, 1998; Vazdarjanova and McGaugh, 1998; Cahill et al., 1999; Fanselow and LeDoux, 1999). The pattern of results obtained in the present experiments indicates that BLA lesions impair mnemonic aspects of Pavlovian fear conditioning, rather than affecting the perfor- mance of the freezing response per se. This claim is supported by the following lines of evidence: (1) the acquisition rate of conditional freezing in rats with BLA lesions was severely impaired (they required at least 10 times more conditioning trials to achieve the levels of performance exhibited by controls), (2) the level of asymptotic performance of rats with BLA lesions was normal (once they achieved asymptote), (3) deficits in freezing to contextual CSs (for example, in rats with post-training BLA lesions) could not be explained by performance deficits insofar as the same rats that exhibited freezing deficits exhibited normal freezing when given extensive reacquisition training (Experiment 2), (4) deficits in freezing to tone CSs (for example, in rats with pretraining BLA lesions) could not be explained by performance deficits insofar as the same rats that exhibited tone freezing deficits exhibited normal context freezing, and (5) the deleterious effect of neurotoxic BLA lesions on conditional freezing was generally pervasive - there was only one set of conditions (pretraining lesions, extensive overtraining, contextual CS) that produced conditional freezing in rats with BLA lesions.

In addition to the data from these lesion experiments, several other lines of evidence are consistent with a role for the BLA in associative processes during fear conditioning (for review, see Maren, 1999). For example, intra-BLA infusions of NMDA receptor antagonists impair the acquisition of conditional fear (Miserendino et al., 1990; Campeau et al., 1992; Fanselow and Kim, 1994; Maren et al., 1996b; Gewirtz and Davis, 1997; Lee and Kim, 1998). Furthermore, reversible inactivation of the BLA during training prevents the acquisition of conditional fear (Helmstetter and Bellgowan, 1994; Muller et al., 1997), and associative neuronal firing develops in the BLA during fear conditioning (Maren et al., 1991; Quirk et al., 1995). Increases in the amplitude of BLA field potentials have been observed after fear conditioning (McKernan and Shinnick-Gallagher, 1997; Rogan et al., 1997), and these changes mirror those associated with the induction of long-term potentiation (LTP) in vivo (Clugnet and LeDoux, 1990; Maren and Fanselow, 1995; Rogan and LeDoux, 1995). Consistent with a role for amygdaloid LTP in fear conditioning, a recent study reports that genetic manipulations that eliminate amygdaloid LTP also impair fear conditioning (Brambilla et al., 1997).

Thus, a wealth of data bolsters the view that the BLA is essential for the learning and memory of Pavlovian fear conditioning in rats. This conclusion departs from that of McGaugh and colleagues (Cahill and McGaugh, 1998; Vazdarjanova and McGaugh, 1998; Cahill et al., 1999), who have suggested that the BLA is not necessary for Pavlovian fear conditioning but is essential only for generating conditional fear responses. Several points argue against this view. First, we have demonstrated clearly that rats with BLA lesions are capable of high levels of freezing under some conditions. In fact, we have demonstrated that individual rats are capable of exhibiting both normal freezing (to an overtrained context CS, for example) and severely impaired freezing (to a tone CS, for example). Second, manipulations that reversibly disrupt the BLA during conditioning yield deficits in conditional fear when the rats are tested later with an intact and functional BLA (Miserendino et al., 1990; Campeau et al., 1992; Fanselow and Kim, 1994; Helmstetter and Bellgowan, 1994; Maren et al., 1996b; Muller et al., 1997). Third, the fact that excitotoxic BLA lesions do not abolish all aversively motivated memories does not imply that the BLA is not involved in the acquisition and expression of Pavlovian fear conditioning (Vazdarjanova and McGaugh, 1998). For example, humans with amyg- 
dala damage (e.g., patient S.M.) do not acquire classically conditioned galvanic skin responses (GSRs), despite exhibiting intact declarative memory for the conditioning experience (Bechara et al., 1995). Likewise, McGaugh and colleagues have shown that rats with BLA lesions exhibit conditional freezing deficits but retain their ability to avoid a compartment in which footshock was delivered (Vazdarjanova and McGaugh, 1998). A similar pattern of results has been reported by Selden and colleagues (1991). This sort of evidence does not diminish the role of the BLA in the acquisition and expression of Pavlovian fear responses, such as freezing or GSRs. It merely indicates that other neural systems engaged during Pavlovian fear conditioning acquire information that can yield explicit recall, in the case of patient S.M., or passive avoidance, in the case of a rat.

The fact that rats with pretraining BLA lesions can acquire contextual freezing after extensive overtraining suggests that another neural system is capable of mediating at least some forms of conditional fear in the absence of the BLA. Importantly, however, this neural system does not appear to be engaged in intact rats undergoing extensive overtraining insofar as savings is not evident in rats with post-training BLA lesions. The locus of this other neural system is unknown, but considerable evidence indicates that the midbrain periaqueductal gray (Bandler and Shipley, 1994; De Oca et al., 1998), superior colliculus (Dean et al., 1988), and cerebellar vermis (Supple et al., 1987) are involved in generating defensive responses, including freezing. In the absence of the BLA these midbrain defense systems may be able to mediate some forms of fear conditioning (e.g., contextual fear conditioning) during extensive overtraining. Further work is required to examine this hypothesis.

In sum, the present results indicate that the BLA has an essential role in the associative processes underlying Pavlovian fear conditioning. The severely retarded acquisition yet normal asymptotic performance of contextual freezing in rats with pretraining BLA lesions and the global deficits in the expression of conditional freezing in rats with post-training BLA lesions indicate that performance interpretations cannot account for the range of deficits exhibited by rats with BLA lesions. Indeed, the robust and nearly global fear conditioning deficits in rats with excitotoxic BLA lesions in the face of extensive overtraining attests to the crucial role for this brain structure in both the formation and storage of fear memories. On the basis of these results, we conclude that performance hypotheses cannot account for the effects of BLA lesions on conditional freezing and, therefore, that the BLA is essential for learning as opposed to performing fear responses.

\section{REFERENCES}

Bandler R, Shipley MT (1994) Columnar organization in the midbrain periaqueductal gray: modules for emotional expression? Trends Neurosci 17:379-389.

Bechara A, Tranel D, Damasio H, Adolphs R, Rockland C, Damasio AR (1995) Double dissociation of conditioning and declarative knowledge relative to the amygdala and hippocampus in humans. Science 269:1115-1118.

Brady JV, Schreiner L, Geller I, Kling A (1954) Subcortical mechanisms in emotional behavior: the effect of rhinencephalic injury upon the acquisition and retention of a conditioned avoidance response in cats. J Comp Physiol Psychol 47:179-186.

Brambilla R, Gnesutta N, Minichiello L, White G, Roylance AJ, Herron CE, Ramsey M, Wolfer DP, Cestari V, Rossi-Arnaud C, Grant SG, Chapman PF, Lipp HP, Sturani E, Klein R (1997) A role for the Ras signaling pathway in synaptic transmission and long-term memory. Nature 390:281-286.
Cahill L, McGaugh JL (1998) Mechanisms of emotional arousal and lasting declarative memory. Trends Neurosci 21:294-299.

Cahill L, Weinberger NM, Roozendaal B, McGaugh JL (1999) Is the amygdala a locus of "conditioned fear"? Some questions and caveats. Neuron 23:227-228.

Campeau S, Davis M (1995) Involvement of the central nucleus and basolateral complex of the amygdala in fear conditioning measured with fear-potentiated startle in rats trained concurrently with auditory and visual conditioned stimuli. J Neurosci 15:2301-2311.

Campeau S, Miserendino MJ, Davis M (1992) Intra-amygdala infusion of the $N$-methyl-D-aspartate receptor antagonist AP5 blocks acquisition but not expression of fear-potentiated startle to an auditory conditioned stimulus. Behav Neurosci 106:569-574.

Clugnet MC, LeDoux JE (1990) Synaptic plasticity in fear conditioning circuits: induction of LTP in the lateral nucleus of the amygdala by stimulation of the medial geniculate body. J Neurosci 10:2818-2824.

Cousens G, Otto T (1998) Both pre- and post-training excitotoxic lesions of the basolateral amygdala abolish the expression of olfactory and contextual fear conditioning. Behav Neurosci 112:1092-1103.

Davis M (1997) Neurobiology of fear responses: the role of the amygdala. J Neuropsychiatry Clin Neurosci 9:382-402.

Dean P, Mitchell IJ, Redgrave P (1988) Responses resembling defensive behaviour produced by microinjection of glutamate into superior colliculus of rats. Neuroscience 24:501-510.

De Oca BM, DeCola JP, Maren S, Fanselow MS (1998) Distinct regions of the periaqueductal gray are involved in the acquisition and expression of defensive responses. J Neurosci 18:3426-3432.

Fanselow MS (1994) Neural organization of the defensive behavior system responsible for fear. Psychon Bull Rev 1:429-438.

Fanselow MS, Kim JJ (1994) Acquisition of contextual Pavlovian fear conditioning is blocked by application of an NMDA receptor antagonist D,L-2-amino-5-phosphonovaleric acid to the basolateral amygdala. Behav Neurosci 108:210-212.

Fanselow MS, LeDoux JE (1999) Why we think plasticity underlying Pavlovian fear conditioning occurs in the basolateral amygdala. Neuron 23:229-232.

Gewirtz JC, Davis M (1997) Second-order fear conditioning prevented by blocking NMDA receptors in amygdala. Nature 388:471-474.

Helmstetter FJ, Bellgowan PS (1994) Effects of muscimol applied to the basolateral amygdala on acquisition and expression of contextual fear conditioning in rats. Behav Neurosci 108:1005-1009.

Killcross S, Robbins TW, Everitt BJ (1997) Different types of fearconditioned behaviour mediated by separate nuclei within amygdala. Nature 388:377-380.

Lavond DG, Kim JJ, Thompson RF (1993) Mammalian brain substrates of aversive classical conditioning. Annu Rev Psychol 44:317-342.

LeDoux J (1998) Fear and the brain: where have we been, and where are we going? Biol Psychiatry 44:1229-1238.

Lee H, Kim JJ (1998) Amygdalar NMDA receptors are critical for new fear learning in previously fear-conditioned rats. J Neurosci 18:8444-8454.

Lee Y, Walker D, Davis M (1996) Lack of a temporal gradient of retrograde amnesia following NMDA-induced lesions of the basolateral amygdala assessed with the fear-potentiated startle paradigm. Behav Neurosci 110:836-839.

Maren S (1996) Synaptic transmission and plasticity in the amygdala. An emerging physiology of fear conditioning circuits. Mol Neurobiol $13: 1-22$.

Maren S (1998) Overtraining does not mitigate contextual fear conditioning deficits produced by neurotoxic lesions of the basolateral amygdala. J Neurosci 18:3088-3097.

Maren S (1999) Long-term potentiation in the amygdala: a mechanism for emotional learning and memory. Trends Neurosci, in press.

Maren S, Fanselow MS (1995) Synaptic plasticity in the basolateral amygdala induced by hippocampal formation stimulation in vivo. J Neurosci 15:7548-7564.

Maren S, Fanselow MS (1996) The amygdala and fear conditioning: has the nut been cracked? Neuron 16:237-240.

Maren S, Poremba A, Gabriel M (1991) Basolateral amygdaloid multiunit neuronal correlates of discriminative avoidance learning in rabbits. Brain Res 549:311-316.

Maren S, Aharonov G, Fanselow MS (1996a) Retrograde abolition of conditional fear after excitotoxic lesions in the basolateral amygdala of rats: absence of a temporal gradient. Behav Neurosci 110:718-726.

Maren S, Aharonov G, Stote DL, Fanselow MS (1996b) $N$-methyl-D- 
aspartate receptors in the basolateral amygdala are required for both acquisition and expression of conditional fear in rats. Behav Neurosci 110:1365-1374.

McGaugh JL, Cahill L, Roozendaal B (1996) Involvement of the amygdala in memory storage: interaction with other brain systems. Proc Natl Acad Sci USA 93:13508-13514.

McKernan MG, Shinnick-Gallagher P (1997) Fear conditioning induces a lasting potentiation of synaptic currents in vitro. Nature 390:607-611.

Miserendino MJ, Sananes CB, Melia KR, Davis M (1990) Blocking of acquisition but not expression of conditioned fear-potentiated startle by NMDA antagonists in the amygdala. Nature 345:716-718.

Muller J, Corodimas KP, Fridel Z, LeDoux JE (1997) Functional inactivation of the lateral and basal nuclei of the amygdala by muscimol infusion prevents fear conditioning to an explicit conditioned stimulus and to contextual stimuli. Behav Neurosci 111:683-691.

Parent MB, Tomaz C, McGaugh JL (1992) Increased training in an aversively motivated task attenuates the memory-impairing effects of post-training $N$-methyl-D-aspartate-induced amygdala lesions. Behav Neurosci 106:789-797.

Parent MB, West M, McGaugh JL (1994) Memory of rats with amygdala lesions induced 30 days after footshock-motivated escape training reflects degree of original training. Behav Neurosci 108:1080-1087.

Quirk GJ, Repa C, LeDoux JE (1995) Fear conditioning enhances shortlatency auditory responses of lateral amygdala neurons: parallel recordings in the freely behaving rat. Neuron 15:1029-1039.

Rogan MT, LeDoux JE (1995) LTP is accompanied by commensurate enhancement of auditory-evoked responses in a fear conditioning circuit. Neuron 15:127-136.

Rogan MT, Staubli UV, LeDoux JE (1997) Fear conditioning induces associative long-term potentiation in the amygdala. Nature 390:604-607.

Sananes CB, Davis M (1992) $N$-methyl-D-aspartate lesions of the lateral and basolateral nuclei of the amygdala block fear-potentiated startle and shock sensitization of startle. Behav Neurosci 106:72-80.

Schulenberg CJ, Riccio DC, Stikes ER (1971) Acquisition and retention of a passive-avoidance response as a function of age in rats. J Comp Physiol Psychol 74:75-83.

Selden NR, Everitt BJ, Jarrard LE, Robbins TW (1991) Complementary roles for the amygdala and hippocampus in aversive conditioning to explicit and contextual cues. Neuroscience 42:335-350.

Spear NE (1973) Retrieval of memory in animals. Psychol Rev 80:163-194.

Supple Jr WF, Leaton RN, Fanselow MS (1987) Effects of cerebellar vermal lesions on species-specific fear responses, neophobia, and tasteaversion learning in rats. Physiol Behav 39:579-586.

Thatcher RW, Kimble DP (1966) Effect of amygdaloid lesions on retention of an avoidance response in overtrained and non-overtrained rats. Psychon Sci 6:9-10.

Vazdarjanova A, McGaugh JL (1998) Basolateral amygdala is not critical for cognitive memory of contextual fear conditioning. Proc Natl Acad Sci USA 95:15003-15007. 